\title{
A new method for producing superior set yogurt, focusing on heat treatment and homogenization
}

\author{
T. Ichimura, ${ }^{1 *}$ ๑ T. Osada,${ }^{1}$ K. Yonekura, ${ }^{2}$ and H. Horiuchi ${ }^{1}$ \\ ${ }_{1}^{1}$ Food Science and Technology Research Laboratories R\&D Division, Meiji Co., Ltd., 1-29-1 Nanakuni, Hachiouji, Tokyo 192-0919, Japan \\ ${ }^{2}$ Food Quality and Safety Research Laboratories R\&D Division, Meiji Co., Ltd., 1-29-1 Nanakuni, Hachiouji, Tokyo 192-0919, Japan
}

\section{ABSTRACT}

Extended shelf life (ESL) processing (i.e., heat treatment at $130^{\circ} \mathrm{C}$ for $2 \mathrm{~s}$ ) is usually not used for producing set yogurt because of the fragility of the curd structure. We investigated the effects of homogenization conducted at higher pressure than the conventional conditions (10 MPa for the first stage and $5 \mathrm{MPa}$ for the second stage) on the curd structure of set yogurt, with a focus on the fat globule size. Each yogurt mix was adjusted at the range of fat globule sizes from 0.45 $\mu \mathrm{m}$ to $1.1 \mu \mathrm{m}$ by a homogenizer and then heated at $95^{\circ} \mathrm{C}$ for $5 \mathrm{~min}$ (conventional heat treatment), $120^{\circ} \mathrm{C}$ for $2 \mathrm{~s}$, ESL processing, or $140^{\circ} \mathrm{C}$ for $2 \mathrm{~s}$. The yogurt mixes were fermented by a common yogurt starter, and the curd texture of the obtained yogurts was evaluated. We observed that the curd hardness and curd firmness of the yogurt were each negatively correlated with the fat globule size regardless of the heat-treatment temperature. Compared with the curd obtained with conventional heat treatment, the ESL-processed curd was extremely fragile, but significantly smooth. With ESL processing, a curd hardness $>40 \mathrm{~g}$, which is a sufficient strength for commercial transport systems, was obtained by making the fat particle size $<0.6 \mu \mathrm{m}$, using 2-stage homogenization pressure: $35 \mathrm{MPa}$ for the first stage and $5 \mathrm{MPa}$ for the second stage. A microscopy analysis indicated that the smaller fat globules reinforce the network structure. The yogurt made by ESL processing and that created with $35+5 \mathrm{MPa}$ homogenization had significant sensory evaluation scores. Our results indicate that the combination of ESL processing and $35+5 \mathrm{MPa}$ homogenization is a novel and useful method for manufacturing set yogurt.

Key words: set yogurt, extended shelf life processing, homogenization, fat globule size

Received September 22, 2021.

Accepted November 30, 2021

*Corresponding author: takefumi.ichimura@meiji.com

\section{INTRODUCTION}

Yogurt is a very popular fermented dairy product that is widely consumed around the world. Various forms of yogurt can be found, including set yogurt, stirred yogurt, and drink yogurt (Aryana and Olson, 2017). The sales of yogurt in Japan in 2019 were approximately US $\$ 4.3$ billion, of which roughly $\$ 1.7$ billion was sales of set yogurt and approximately $\$ 1.1$ billion was sales of stirred yogurt. The high share of set yogurt is thus a feature of the Japanese market. Japanese consumers widely accept set yogurt and regard plain yogurt in particular as a traditional and clean label yogurt.

Texture is one of the most important characteristics of set yogurt quality (Sodini et al., 2004). Good texture leads to superior ratings for a product. Japanese consumers tend to prefer a soft and smooth texture, and a too hard or rough texture is not desired. It is thus necessary to continuously develop methods to obtain smoother set yogurt. However, in Japan, food products are also required to include no harmful microorganisms and no foreign substances but should also have no offtaste or off-flavor, yet a normal appearance. The appearance is one of the important food elements perceived by consumers, and set yogurt should have a smooth, whey-free appearance (Lucey and Singh, 1997). Set yogurt must therefore be strong enough to withstand the vibrations of trucks in which it is shipped, because it is often transported over a long distance before it reaches consumers (Horiuchi et al., 2009). Set yogurt products are also occasionally placed sideways in a store display; even so, set yogurt needs to have a shape-retaining capacity that does not collapse to the extent possible. The better set yogurt for a consumer is the one that has both pleasing texture (especially smoothness) and sufficient curd strength. In this study, we investigated heat treatment and homogenization conditions as a means to obtain a smoother texture for set yogurt compared with the conventional method.

The term "extended shelf life" (ESL) processing is usually used to indicate heat treatment at 125 to $140^{\circ} \mathrm{C}$ for 1 to $10 \mathrm{~s}$ (IDF, 2018). In Japan, milk is usually heated at $130^{\circ} \mathrm{C}$ for $2 \mathrm{~s}$ (Ohkubo et al., 2019), but yo- 
gurt mix is usually heated at 90 to $95^{\circ} \mathrm{C}$ for 5 to $10 \mathrm{~min}$, and not at $130^{\circ} \mathrm{C}$ for $2 \mathrm{~s}$ (Sodini et al., 2004; Karam et al., 2013). Heating conditions at 90 to $95^{\circ} \mathrm{C}$ for 5 to $10 \mathrm{~min}$ ensure that the denaturation rate of $\beta$-LG is $\geq 90 \%$ (Dannenberg and Kessler, 1988). Heat treatment at $\geq 120^{\circ} \mathrm{C}$ together with $14.5 \mathrm{MPa}+3.6 \mathrm{MPa}$ homogenization reduces the firmness of yogurt regardless of the denaturation rate of whey protein (Savello and Dargan, 1995, 1997). For example, the viscosity of $20 \%$ solid yogurt sterilized at $143^{\circ} \mathrm{C}$ for 6 s together with $20 \mathrm{MPa}+5 \mathrm{MPa}$ homogenization is lowered to about half of the viscosity of $20 \%$ solid yogurt heated at $85^{\circ} \mathrm{C}$ for $30 \mathrm{~min}$ and treated with $20 \mathrm{MPa}+5 \mathrm{MPa}$ homogenization (Krasaekoopt et al., 2004). Therefore, heat treatment at $\geq 120^{\circ} \mathrm{C}$ has not usually been used as a manufacturing condition for yogurt.

Our prior research demonstrated that ESL-processed yogurt has lower curd strength but a very smooth texture, and we hypothesized that smooth yogurt can be produced by enhancing the curd strength of the yogurt made with an ESL-processed yogurt mix. Savello and Dargan $(1995,1997)$ examined a method of combining the UF membrane concentration with 100 to $130^{\circ} \mathrm{C}$ heat treatment, but the method posed 2 problems: a membrane facility is required, and a high amount of permeate is generated. To the best of our knowledge, there has been no example of ESL processing being successfully used in the production of yogurt.

Yogurt mix is usually homogenized using 10 to 20 $\mathrm{MPa}$ as the first-stage pressure and $5 \mathrm{MPa}$ as the second-stage pressure (i.e., the conventional homogenization conditions) and at a temperature range between 55 and $65^{\circ} \mathrm{C}$ (Lee and Lucey, 2010). After homogenization, the size of the fat globules reduces, and the fat globules' surface area increases. The newly formed fat globule surface is coated mainly by casein, and it can interact with the protein networks (Lucey et al., 1998; Lee and Sherbon, 2002; Michalski et al., 2002). The use of homogenization reduces whey separation, increases whiteness, and enhances the consistency of yogurts (Tamime and Robinson, 2007b). We thus speculated that higher-pressure homogenization than the conventional condition could increase the curd hardness of the yogurt made with an ESL-processed yogurt mix. Many studies have examined the influences of heat treatment and homogenization on yogurt texture, but to the best of our knowledge, the effects of combinations of higherthan-conventional homogenization pressure and ESL processing on the rheological and sensory properties of yogurt have not been reported.

We conducted the present study to determine whether the combination of ESL processing and higher-thanconventional homogenization pressure could produce a set yogurt with a smooth texture and a strong curd structure.

\section{MATERIALS AND METHODS}

\section{Preparation of Bulk Starter Culture}

The culture LB81, which contains Lactobacillus delbrueckii ssp. bulgaricus 2038 and Streptococcus thermophilus 1131, was used in this study. This starter culture has been used in the commercial production of Meiji Bulgaria Yogurt LB81 in Japan since 1993. The culture LB81 stored at $-80^{\circ} \mathrm{C}$ was inoculated $(0.15 \%$, wt/wt) into heated $10 \%$ (wt/wt) skim milk $\left(95^{\circ} \mathrm{C}, 10\right.$ min) and then incubated at $37^{\circ} \mathrm{C}$ to reach an acidity of $0.75 \%$. After fermentation, the LB81 starter culture was cooled immediately to $5^{\circ} \mathrm{C}$ (yogurt bulk starter culture). The acidity was determined by titrating a $9.0-\mathrm{g}$ yogurt sample with $0.1 \mathrm{~N}$ sodium hydroxide, using phenolphthalein as an indicator. The yogurt bulk starter was stored at $5^{\circ} \mathrm{C}$ and used within 1 wk.

\section{Set Yogurt Production}

The yogurt mix contained $3.0 \%$ (wt/wt) fat and $9.5 \%$ (wt/wt) SNF and was obtained by mixing raw milk, skim milk powder, and water. The raw milk and skim milk powder were supplied by Meiji Co., Ltd. facilities. The yogurt mix was prewarmed at $75^{\circ} \mathrm{C}$ and then homogenized at $10 \mathrm{MPa}$ (first stage) $+5 \mathrm{MPa}$ (second stage), $15+5 \mathrm{MPa}, 25+5 \mathrm{MPa}, 35+5 \mathrm{MPa}$, or $40+5 \mathrm{MPa}$, before heat treatment. Homogenization was performed using a homogenizer (Sanwa Engineering).

The yogurt mix was heated at $95^{\circ} \mathrm{C}$ for $5 \mathrm{~min}$, at $120^{\circ} \mathrm{C}$ for $2 \mathrm{~s}$, at $130^{\circ} \mathrm{C}$ for $2 \mathrm{~s}$ (i.e., the ESL processing), or at $140^{\circ} \mathrm{C}$ for $2 \mathrm{~s}$. Heat treatment at $95^{\circ} \mathrm{C}$ for 5 min was treated with the Vat heat treatment. The heat treatments at $120^{\circ} \mathrm{C}$ for $2 \mathrm{~s}$, at $130^{\circ} \mathrm{C}$ for $2 \mathrm{~s}$, and at $140^{\circ} \mathrm{C}$ for $2 \mathrm{~s}$ were applied with an indirect plate exchange system (Powerpoint International, Saitama, Japan). In this study, we defined the control condition as heat treatment at $95^{\circ} \mathrm{C}$ for $5 \mathrm{~min}$ and homogenization at $10+5 \mathrm{MPa}$. After heat treatment, the yogurt mix samples were immediately cooled to $37^{\circ} \mathrm{C}$ and then inoculated with $3 \%$ (wt/wt) of the yogurt bulk starter culture. After the yogurt mix and yogurt bulk starter culture were mixed, $80 \mathrm{~g}$ of the mixture was placed in $100-\mathrm{mL}$ polystyrene cups, and $400 \mathrm{~g}$ of the mixture was placed in $550-\mathrm{mL}$ paper cups. The yogurt mix was fermented with low-temperature $\left(37^{\circ} \mathrm{C}\right)$ reduced dissolved oxygen fermentation (Horiuchi et al., 2009) until the acidity reached $0.7 \%$, equivalent to $\mathrm{pH}$ 4.6. After 
fermentation, the yogurts were stored at $5^{\circ} \mathrm{C}$ for $1 \mathrm{~d}$ before evaluation.

\section{Particle Size Distribution}

The distribution of the sizes of the fat particles of the yogurt mix was obtained by a laser diffraction scattering method with the SALD2200 laser diffraction particle size analyzer (Shimadzu). Yogurt mix was added into the circulating cell of the apparatus containing deionized water. Triplicate measurements were taken at $25^{\circ} \mathrm{C}$, and the surface area mean diameters $\left(\mathrm{d}_{3,2}\right)$ were recorded.

\section{Physical Characterization of the Yogurt}

The physical characterization of the yogurt was determined by the curd hardness, curd firmness, penetration angle, and the shape retention capacity. The curd hardness and curd firmness of yogurt represents the tolerance to vibration during transport. The penetration angle represents the smoothness of the yogurt, and the shape retention capacity represents tolerance to collapse when placed sideways (e.g., in a store display).

The curd hardness, the curd firmness, and the penetration angle of the yogurt were measured by a CurdmeterMAX ME-500 (Asuka Kiki). The pressure was applied by a yogurt knife. A load of $2.5 \mathrm{~g}$ was applied per second, and the weight at which the surface fractured was taken as the curd hardness. The total positive area on the chart represents the curd firmness, obtained by a method similar to that described by Meletharayil et al. (2016). We used the penetration angle of the elastic surface curve as an index of smoothness (Horiuchi et al., 2009). A smaller penetration angle represents a smoother tissue. The yogurt samples in 100$\mathrm{mL}$ polystyrene cups were taken out of the refrigerator at $5^{\circ} \mathrm{C}$ just before the measurement of curd hardness, curd firmness, and penetration angle, simulating the temperature during transportation.

Both the curd hardness and curd stickiness are related to yogurt's resistance to crumbling when the yogurt is placed sideways. We defined the combination of curd hardness and curd stickiness as the shape retention capacity. The shape retention capacity of the yogurt was determined by a shape retention test (Figure 1A). Yogurt samples in 550-mL paper cups were gently turned over, and we defined the time that it took for the yogurt to peel off from the cup and move out of the cup as the disintegration time of the yogurt curd (Figure 1B). Set yogurt paper cups that are commonly used in Japan were used for these measurements. The dimensions of the paper cups used for shape retention test are shown in Figure 1C. The test was performed in quadruplicate.
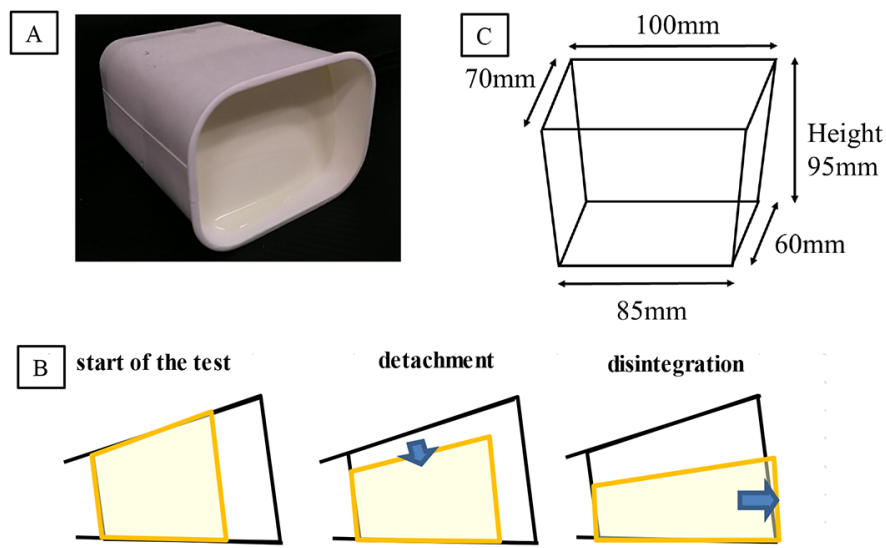

Figure 1. (A) The appearance of the cups used in the shape retention test. (B) The flow of the shape retention test. The time that it took for the yogurt to move out of the container from the start of the test was determined. (C) The dimensions of the 550-mL yogurt cup used for the shape retention test.

The shape retention capacity is a physical characteristic related to the shape of the cup in which the product is placed and should be evaluated according to the form actually released. We must therefore point out that the shape retention capacity of yogurt cannot be compared when the shapes of its containers are different. In addition, the marketed yogurt product has a lid, and the shape is thus maintained for a longer time. The yogurt samples in $550-\mathrm{mL}$ paper cups were taken out of the refrigerator at $5^{\circ} \mathrm{C}$ just before the shape retention test and were placed sideways at $25^{\circ} \mathrm{C}$, simulating the gradient change of temperature of the yogurt in stores.

The degree of syneresis was obtained using a centrifugation method. Yogurt samples (40 g) in $50-\mathrm{mL}$ tubes were centrifuged at $1,182 \times g$ for $10 \mathrm{~min}$ at $25^{\circ} \mathrm{C}$. The degree of syneresis was defined as the grams of supernatant separated per $100 \mathrm{~g}$ of yogurt.

\section{Sensory Evaluation}

The sensory evaluation test of the yogurts was carried out with 22 trained sensory panelists (16 females and 6 males, aged 23-45 yr) of Meiji Co. Ltd. The sensory evaluation panel was selected from panels of individuals with a sharp sense of 5 flavors (sweetness, saltiness, sourness, bitterness, and umami). The yogurt samples in 100-mL polystyrene cups were taken out of the refrigerator at $5^{\circ} \mathrm{C}$ just before the sensory evaluation, which took place in a sensory room with an ambient temperature of 20 to $23^{\circ} \mathrm{C}$.

Each yogurt sample was evaluated as an absolute rating on a 5 -point scale $(1=$ very weak to $5=$ very strong) for each evaluation term. The sensory evaluation was carried out with 5 evaluation terms: overall 
Table 1. Sensory evaluation terms used for evaluation of yogurt samples

\begin{tabular}{ll}
\hline Term $^{1}$ & Definition \\
\hline Smoothness & The degree to which the yogurt easily collapses in the mouth without a feeling graininess, roughness, or sandiness \\
Fillingness & The degree of satisfaction, as if one had eaten more food \\
Richness & The degree to which the texture and creamy taste are felt when the yogurt is swallowed using the tongue \\
Mildness & The degree of having soft flavor and taste \\
Overall acceptability & Overall preference of the food
\end{tabular}

${ }^{1}$ Intensity, on a 5 -point scale: $1=$ very low, $5=$ very high.

acceptability, smoothness, fillingness, richness, and mildness (Table 1).

\section{Confocal Laser Scanning Microscopy}

We evaluated the distribution of milk fat and protein in the yogurt by confocal laser scanning microscopy (CLSM) with an upright microscope (Bx61, Olympus). A portion $1 \mathrm{~cm}$ below the surface of the yogurt as a measurement sample was cut out to a length of $5 \mathrm{~mm}$ and a width of $1 \mathrm{~mm}$ and placed on a singlehole slide glass. Milk fat and milk protein were stained by dropping $10 \mu \mathrm{L}$ of Nile mix staining solution. The method of preparing the Nile mix staining solution was as described (Auty et al., 2001). A cover glass was placed on the stained sample and used for observation, and $633 \mathrm{~nm}$ and $488 \mathrm{~nm}$ were selected as the excitation wavelengths.

\section{Statistical Analysis}

A one-way repeated-measures ANOVA and TukeyKramer adjustment were used to investigate the effects of differences in test conditions on the yogurts' physical properties and sensory evaluation. The data were analyzed using Bellcurve for Excel (ver. 3.22, Social Survey Research Information) to find significant differences among the samples. Differences were considered significant when $P<0.05$.

\section{RESULTS}

\section{Effects of the Heat-Treatment Temperature and Fat Globule Size on the Physical Characteristics of Yogurt}

Table 2 provides the test conditions of heat treatment and homogenization and lists the fat globule sizes of the obtained yogurt mix and physical characteristics of the fermented yogurt. The fat globule sizes ranged from 0.45 to $1.10 \mu \mathrm{m}$. As the homogenization pressure increased, the fat globule size of the yogurt mix gradually became smaller. The results indicated that the heat treatment conditions did not affect the fat globule size.
The curd hardness and the curd firmness were both greatly affected by the heat-treatment temperature and homogenization pressure. As the heat-treatment temperature increased, the curd hardness and the curd firmness of the yogurt gradually became lower, and as the homogenization pressure increased, the curd hardness and the curd firmness of the yogurt gradually became higher. Regarding the penetration angle, the angles observed for the yogurt made by ESL processing and $140^{\circ} \mathrm{C}$ heat treatment were significantly lower than those obtained with the $95^{\circ} \mathrm{C}$ heat treatment. Table 2 indicates that the yogurt made by ESL processing and $140^{\circ} \mathrm{C}$ heat treatment had significantly smooth tissues. The penetration angle was more influenced by the heat-treatment temperature than the homogenization pressure.

Figure 2 illustrates the relationships between the fat globule size of the yogurt mix and the curd hardness of the fermented yogurt. The curd hardness of the yogurt was negatively correlated with the fat globule size of the yogurt mix regardless of the heat-treatment temperature. Compared with the curd obtained with conventional heat treatment, the curd obtained with ESL processing was extremely fragile. With the ESL processing, a curd hardness $>40 \mathrm{~g}$, which is a sufficient strength for commercial transport systems (Horiuchi et al., 2009), was obtained by making the fat particle size $<0.6 \mu \mathrm{m}$. Under those conditions, the curd hardness and the curd firmness were as high as or better than those obtained using the control conditions, and the penetration angle was significantly lower.

\section{Characteristics of the Yogurt Made by ESL Processing and Higher-Than-Conventional Homogenization Pressure}

We evaluated the physical properties of the yogurt made by the combination of ESL processing and higherpressure homogenization $(35+5 \mathrm{MPa})$ compared with conventional conditions in detail, based on yogurts' sufficient curd hardness, curd firmness, and penetration angle. We prepared the yogurt under the conditions listed in Table 3. The fat globule size of the yogurt mix homogenized at $35+5 \mathrm{MPa}$ was approx. $0.5 \mu \mathrm{m}$, 
Table 2. Conditions for making yogurt samples and the physical characteristics of the yogurts

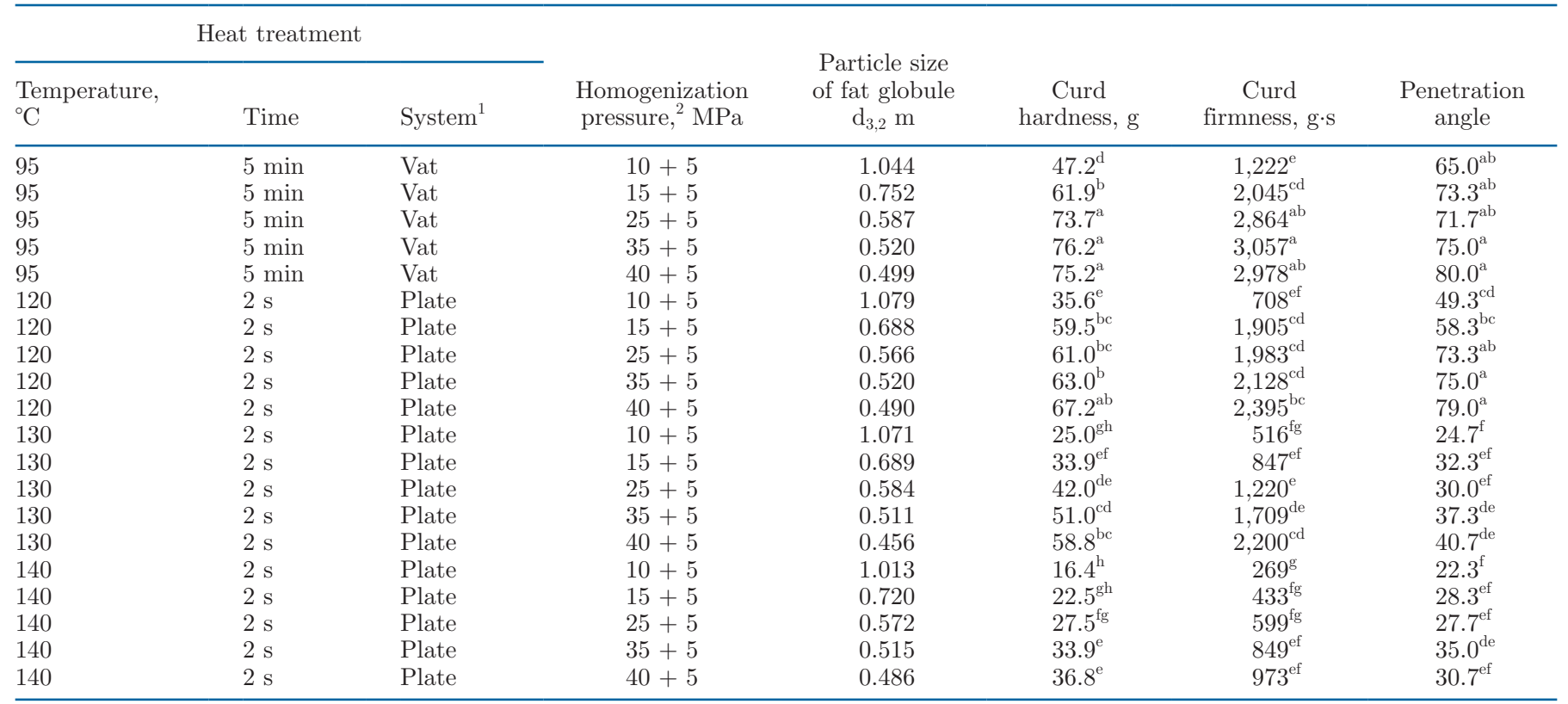

${ }^{\mathrm{a}-\mathrm{g}}$ Values with different letters in the same column are significantly different $(P<0.05)$.

${ }^{1}$ Vat $=$ vat heat treatment; plate $=$ indirect plate exchange system (Powerpoint International Ltd.).

${ }^{2}$ Double-stage homogenization (first stage and second stage) at $75^{\circ} \mathrm{C}$.

whereas the fat globule size at conventional pressure $(10+5 \mathrm{MPa})$ was approximately $1.1 \mu \mathrm{m}$.

Table 4 summarizes the physical properties of the yogurt made from each yogurt mix. In the evaluation of the curd hardness, curd firmness, and disintegration time, the yogurt made by ESL processing and conventional-pressure homogenization was the worst of all samples. The $35+5 \mathrm{MPa}$ homogenization improved

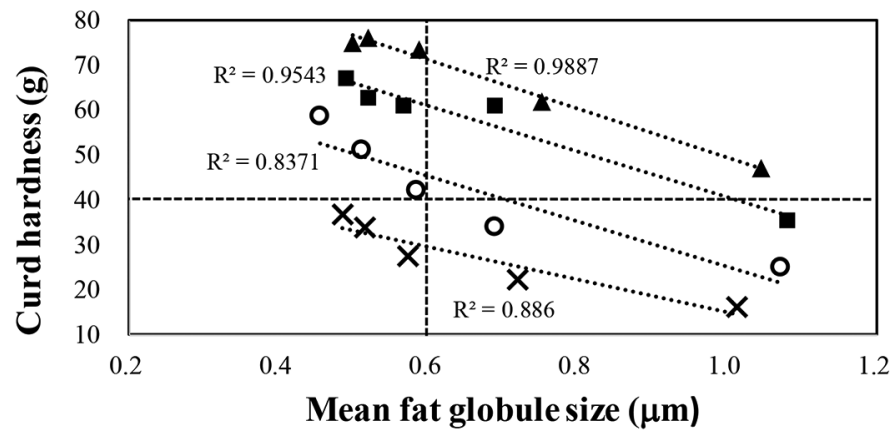

Figure 2. The relationship between the fat globule size of the yogurt mix and the yogurt curd firmness: $(\boldsymbol{\Delta})$ heat treatment at $95^{\circ} \mathrm{C}$ for $5 \mathrm{~min},(\boldsymbol{\square})$ heat treatment at $120^{\circ} \mathrm{C}$ for $2 \mathrm{~s}$, (O) heat treatment at $130^{\circ} \mathrm{C}$ for $2 \mathrm{~s}$, and $(\times)$ heat treatment at $140^{\circ} \mathrm{C}$ for $2 \mathrm{~s}$. The horizontal dotted line shows a curd hardness of $40 \mathrm{~g}$ that can sufficiently withstand the vibration of transportation (Horiuchi et al., 2009). The vertical dotted line indicates the fat globule size obtained when the curd hardness of yogurt made by extended shelf life processing exceeds $40 \mathrm{~g}$. The diagonal dotted line is the regression line of the fat globule size and the curd hardness. the curd hardness, curd firmness and the disintegration time, but increased the penetration angle. The syneresis value of the yogurt made by the combination of ESL processing and $35+5 \mathrm{MPa}$ homogenization was the lowest of all of the samples. In the evaluation of the penetration angle, the yogurt made by ESL processing and conventional-pressure homogenization was the best of all samples, and the yogurt made by $95^{\circ} \mathrm{C}$ heat treatment and $35+5 \mathrm{MPa}$ homogenization was the worst of all samples.

\section{Sensory Evaluation of the Yogurt}

We carried out sensory evaluations with 4 types of yogurts made by (1) the control condition, (2) ESL processing, (3) $35+5 \mathrm{MPa}$ homogenization, and (4) ESL processing and $35+5 \mathrm{MPa}$ homogenization. The mean sensory evaluation scores of the 4 types of yogurt are depicted in Figure 3. The yogurt made by ESL processing had significantly higher evaluation scores for smoothness, fillingness, and richness compared with the control condition (i.e., $95^{\circ} \mathrm{C}$ for $5 \mathrm{~min}, 10+5 \mathrm{MPa}$ ). Compared with the yogurt made under the control conditions, the yogurt made by $35+5 \mathrm{MPa}$ homogenization had significantly higher evaluation scores for fillingness but significantly lower evaluation scores for smoothness and overall acceptability. The yogurt made by ESL processing and $35+5 \mathrm{MPa}$ homogenization had significantly higher evaluation scores for mildness and 
Table 3. Conditions for making the yogurt samples

\begin{tabular}{|c|c|c|c|c|}
\hline Sample name & \multicolumn{3}{|c|}{ Heat treatment } & $\begin{array}{l}\text { Homogenization } \\
\text { pressure, }{ }^{2} \mathrm{MPa}\end{array}$ \\
\hline Control & 95 & $5 \min$ & Vat & $10+5$ \\
\hline $35+5 \mathrm{MPa}$ homogenization & 95 & $5 \mathrm{~min}$ & Vat & $35+5$ \\
\hline ESL-processing $^{3}$ and $35+5 \mathrm{MPa}$ homogenization & 130 & $2 \mathrm{~s}$ & Plate & $35+5$ \\
\hline
\end{tabular}

${ }^{1}$ Vat $=$ vat heat treatment; plate $=$ indirect plate exchange system (Powerpoint International Ltd.).

${ }^{2}$ Double-stage homogenization (first stage and second stage) at $75^{\circ} \mathrm{C}$.

${ }^{3} \mathrm{ESL}=$ extended shelf life; heat treatment at $130^{\circ} \mathrm{C}$ for $2 \mathrm{sec}$.

overall acceptability compared with the yogurt made by ESL processing, and had significantly higher evaluation scores for smoothness, mildness, and overall acceptability compared with the yogurt made by $35+5$ $\mathrm{MPa}$ homogenization. As a result, the yogurt made by ESL processing and $35+5 \mathrm{MPa}$ homogenization had significantly higher scores than the yogurt made using the control conditions for all of the sensory evaluation terms.

\section{Confocal Laser Scanning Microscopy}

We used CLSM to observe the microstructure of the yogurts prepared under the conditions shown in Table 3. The CLSM images of the yogurt samples are given in Figure 4. All of the yogurts had a heterogeneous structure with protein aggregates and voids. Smaller fat globules were embedded in the casein networks, and larger fat globules were dispersed between the casein network structures. The relationship between the size of the fat globules and the localization of the fat globules was similar to that reported by Ciron et al. (2012) and Michalski et al. (2002). The yogurt subjected to ESL processing tended to have a thin structure of protein aggregates, whereas in the yogurt subjected to the $95^{\circ} \mathrm{C}$ heat treatment, large protein aggregates were observed. Regarding the casein network structure, the yogurt made by $35+5 \mathrm{MPa}$ homogenization had a higher-density structure, and the yogurt made by ESL processing had a lower-density structure. The structures of the yogurt networks were thus affected by both the heat-treatment temperature and the fat particle size.

\section{DISCUSSION}

\section{Effects of the Heat-Treatment Temperature and the Homogenization Pressure on the Physical Properties and Sensory Evaluation of the Yogurt}

The quality of yogurt is affected by factors such as the ingredients, starter, and manufacturing processes (Sodini et al., 2004; Tamime and Robinson, 2007a; Lee and Lucey, 2010; Karam et al., 2013; Aryana and Olson, 2017). In this study, we focused on the heat-treatment temperature and the homogenization pressure, and our results demonstrate that the curd hardness of the yogurt was negatively correlated with the fat globule size of the yogurt mix regardless of the heat-treatment temperature (Figure 2). The results clarified that even when ESL processing was performed, a yogurt which had sufficient strength for commercial transport systems could be obtained by performing higher-pressure homogenization than control conditions; for example, $35+5 \mathrm{MPa}$.

The shape retention capacity is an index of the overall resistance of set yogurt to collapse, including the strength of adhesion and the strength of the structure. In light of the improvement of the shape retention

Table 4. Average $(\mathrm{n}=4)$ physical characterization of yogurts

\begin{tabular}{|c|c|c|c|c|c|c|}
\hline Sample name & $\begin{array}{l}\text { Particle size } \\
\text { of fat globule, } \\
\qquad \mathrm{d}_{3,2} \mathrm{~m}\end{array}$ & $\begin{array}{c}\text { Curd } \\
\text { hardness, g }\end{array}$ & $\begin{array}{l}\text { Curd } \\
\text { firmness, } g \cdot s\end{array}$ & $\begin{array}{l}\text { Disintegration } \\
\text { time, min }\end{array}$ & Syneresis \% & $\begin{array}{c}\text { Penetration } \\
\text { angle }\end{array}$ \\
\hline Control & 1.121 & $54.6^{\mathrm{ab}}$ & $1,607^{\mathrm{b}}$ & $23.3^{\mathrm{bc}}$ & $22.9^{\mathrm{a}}$ & $66.7^{\mathrm{b}}$ \\
\hline ESL processing ${ }^{1}$ & 1.106 & $26.9^{\mathrm{c}}$ & $578^{\mathrm{c}}$ & $12.8^{\mathrm{c}}$ & $19.8^{\mathrm{a}}$ & $25.7^{\mathrm{d}}$ \\
\hline $35+5 \mathrm{MPa}$ homogenization & 0.523 & $67.4^{\mathrm{a}}$ & $2,436^{\mathrm{a}}$ & $46.5^{\mathrm{a}}$ & $14.3^{\mathrm{b}}$ & $78.3^{\mathrm{a}}$ \\
\hline ESL processing ${ }^{1}$ and $35+5 \mathrm{MPa}$ & 0.509 & $48.6^{\mathrm{b}}$ & $1,587^{\mathrm{b}}$ & $36.5^{\mathrm{ab}}$ & $9.3^{\mathrm{c}}$ & $39.0^{\mathrm{c}}$ \\
\hline
\end{tabular}

${ }^{\mathrm{a}-\mathrm{c}}$ Values with different letters in the same column are significantly different $(P<0.05)$.

${ }^{1} \mathrm{ESL}=$ extended shelf life; heat treatment at $130^{\circ} \mathrm{C}$ for $2 \mathrm{~s}$. 


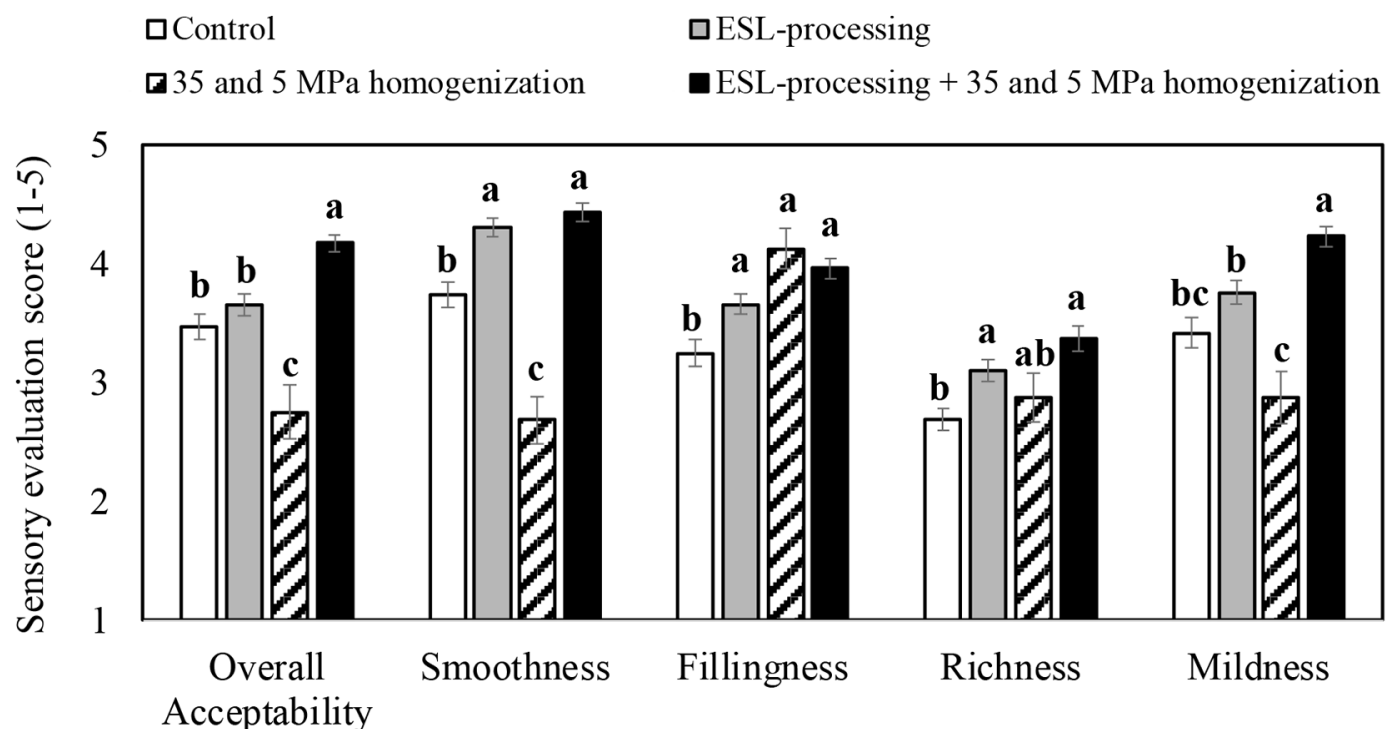

Sensory term

Figure 3. Sensory evaluation scores of the yogurts. Control: heat treatment at $95^{\circ} \mathrm{C}$ for $5 \mathrm{~min}$ and homogenization at $10 \mathrm{MPa}$ and $5 \mathrm{MPa}$. Extended shelf life (ESL) processing: heat treatment at $130^{\circ} \mathrm{C}$ for $2 \mathrm{~s}$ and homogenization at $10+5 \mathrm{MPa}$. The $35+5 \mathrm{MPa}$ homogenization: heat treatment at $95^{\circ} \mathrm{C}$ for $5 \mathrm{~min}$ and homogenization at $35+5 \mathrm{MPa}$. ESL processing and $35+5 \mathrm{MPa}$ homogenization: heat treatment at $130^{\circ} \mathrm{C}$ for $2 \mathrm{~s}$ and homogenization at $35+5 \mathrm{MPa}$. Plots with different characters $(\mathrm{a}-\mathrm{c})$ on the same sensory term were significantly different $(P<0.05)$. The error bars represent SD.

capacity observed herein, it is apparent that higherpressure homogenization is an effective means to prevent set yogurt from collapsing.

The physical characteristics of set yogurt are related to various factors such as protein-protein interaction, protein-fat interaction, the $\mathrm{pH}$ at the end of the fermentation, and the cooling temperature (Singh et al., 1996; Teo et al., 1997; Tamime and Robinson, 2007c). During a heat treatment at $>100^{\circ} \mathrm{C}$, the interaction of $\alpha-\mathrm{LA}$ with the casein micelles occurred more slowly than the interaction of $\beta$-LG with the casein micelles (Plock et al., 1997), and during heat treatment at $>100^{\circ} \mathrm{C}$, casein micelles aggregated into larger particles and dissociated into soluble casein (Tamime and Robinson, 2007c).

Mottar et al. (1989) reported that UHT sterilization $\left(135-150^{\circ} \mathrm{C}\right.$ for $\left.1-10 \mathrm{~s}\right)$ resulted in a lower $\alpha$-LA denaturation rate, larger casein micelle sizes, and a rougher surface of casein micelles compared with batch heat treatment of $95^{\circ} \mathrm{C}$ for $10 \mathrm{~min}$. We therefore speculated that the causes of the decrease in the curd firmness of the yogurt made by ESL processing and $140^{\circ} \mathrm{C}$ heat treatment were (1) the decrease in the number of network-forming particles due to casein micelles' enlargement and solubilization, and (2) the decrease in the interaction among casein micelles due to surface roughening.

There have been several studies of the relationship between the emulsification method and the physical characteristics of set yogurt. Ciron et al. (2012) re- ported that low-fat yogurt made by a microfluidizer had greater creaminess than low-fat yogurt made by a homogenizer. The relationship between the fat globule size and the physical characteristics of set yogurt has not been extensively investigated. Michalski et al. (2002) reported that when the size of fat globules was $\geq 1.4 \mu \mathrm{m}$, the smaller the size of the fat globules was, the higher the viscosity of the yogurt was obtained. Our present findings reveal that fat globules contribute significantly to the hardness and the firmness of yogurt when the fat globule size is $\leq 1 \mu \mathrm{m}$. We observed that when the size of the fat globules was halved, there were 8 times as many particles and the surface area of the fat globules was doubled. We thus presume that reducing the size of the fat globules contributed to the strengthening of the yogurt by 2 effects: (1) by increasing the number of fat globules taken into the network, and (2) by increasing the interaction surface between the fat globules and the network. In this study, the $\mathrm{pH}$ values at the end of fermentation and the cooling conditions were the same for all samples, and we thus speculated that the differences in physical properties among the samples were due mainly to the differences in proteinprotein interactions and protein-fat interactions.

It is important to evaluate physical properties such as curd firmness and syneresis because most consumers are concerned about the appearance of yogurt. In this study, the higher-than-conventional homogenization pressure improved the curd hardness, the curd firmness, 

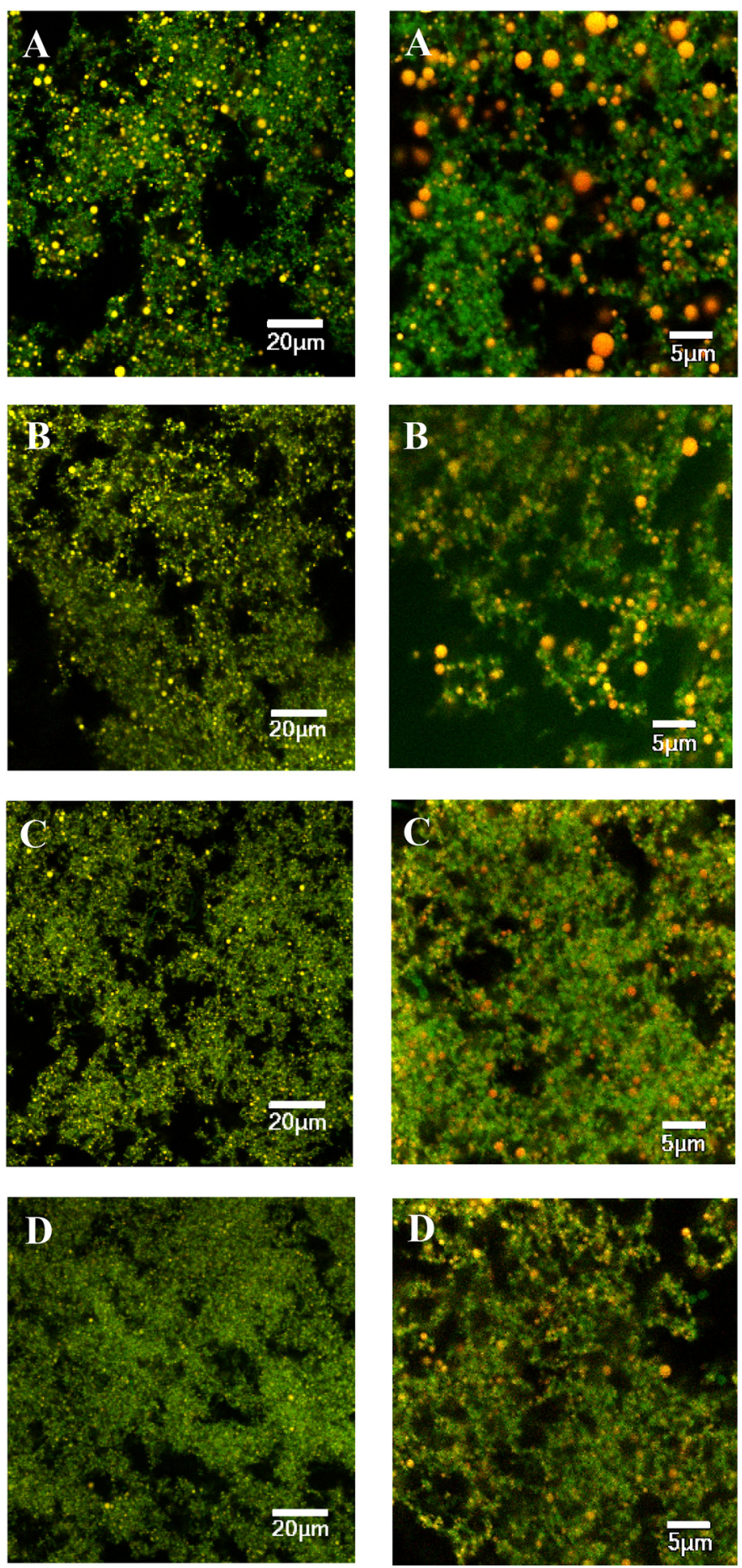

Figure 4. Confocal micrographs of yogurts with different conditions of homogenization and heat-treatment temperature. (A) Heat treatment at $95^{\circ} \mathrm{C}$ for $5 \mathrm{~min}$ and homogenization at $10+5 \mathrm{MPa}$. (B) Heat treatment at $130^{\circ} \mathrm{C}$ for $2 \mathrm{~s}$ and homogenization at $10+5 \mathrm{MPa}$. (C) Heat treatment at $95^{\circ} \mathrm{C}$ for $5 \mathrm{~min}$ and homogenization at $35+5$ $\mathrm{MPa}$. (D) Heat treatment at $130^{\circ} \mathrm{C}$ for $2 \mathrm{~s}$ and homogenization at $35+5 \mathrm{MPa}$. The protein networks are green, and the fat globules are yellow. and the disintegration time of the yogurt made by ESL processing. The yogurt that was made by ESL processing together with $35+5 \mathrm{MPa}$ homogenization had a significantly higher sensory evaluation score than the control condition. From the above results, we concluded that ESL processing plus $35+5 \mathrm{MPa}$ homogenization is an effective method for producing superior set yogurt that has both curd strength and a good texture. Our findings can be used to develop new yogurt products and improve the products on the market.

\section{Analysis of Curd Structure by CLSM}

We verified the effect of the heat-treatment temperature and homogenization pressure on the microstructural characteristics of yogurt by performing a CLSM examination, which clarified that heat treatment at $130^{\circ} \mathrm{C}$ reduced the network density of the yogurt. It was reported that casein micelles heated at $140^{\circ} \mathrm{C}$ had a confirmed filament structure, and during fermentation, linkage by a linear substance was observed rather than a fusion of casein micelles (Mottar et al., 1989). We thus suspect that the yogurt made by ESL processing has a smaller network structure unit and a weaker binding force, resulting in a thinner network and weaker hardness and firmness. We also speculate that the small unit of the network structure increases the surface area of hydration and contributes to a reduction of whey separation.

Our results confirmed that the yogurt made by $35+5$ MPa homogenization had increased network density. An increase in network density indicates that the network volume has increased due to the inclusion of fat globules inside as well as on the surface. Fat globules emulsified by casein can interact with the casein network structure (Michalski et al., 2002), and we thus suspect that the $35+5 \mathrm{MPa}$ homogenization made fat globules a component of the network and strengthened the curd of yogurt made by ESL processing (Figure 5). Several unclear points remain, such as the role of finely divided milk fat globules in the fermentation process and the differences in the yogurt microstructure due to differences in the production methods. To clarify the mechanisms underlying changes in physical properties that depend on the heat-treatment temperature and fat globule size, it is necessary to observe in more detail the formation process of the yogurt networks and the structure of the yogurt during fermentation.

\section{Possible New Industrial Process}

The results of this study can enable a more sophisticated design of the manufacturing process used for set yogurt. Heating the yogurt mix with ESL processing 


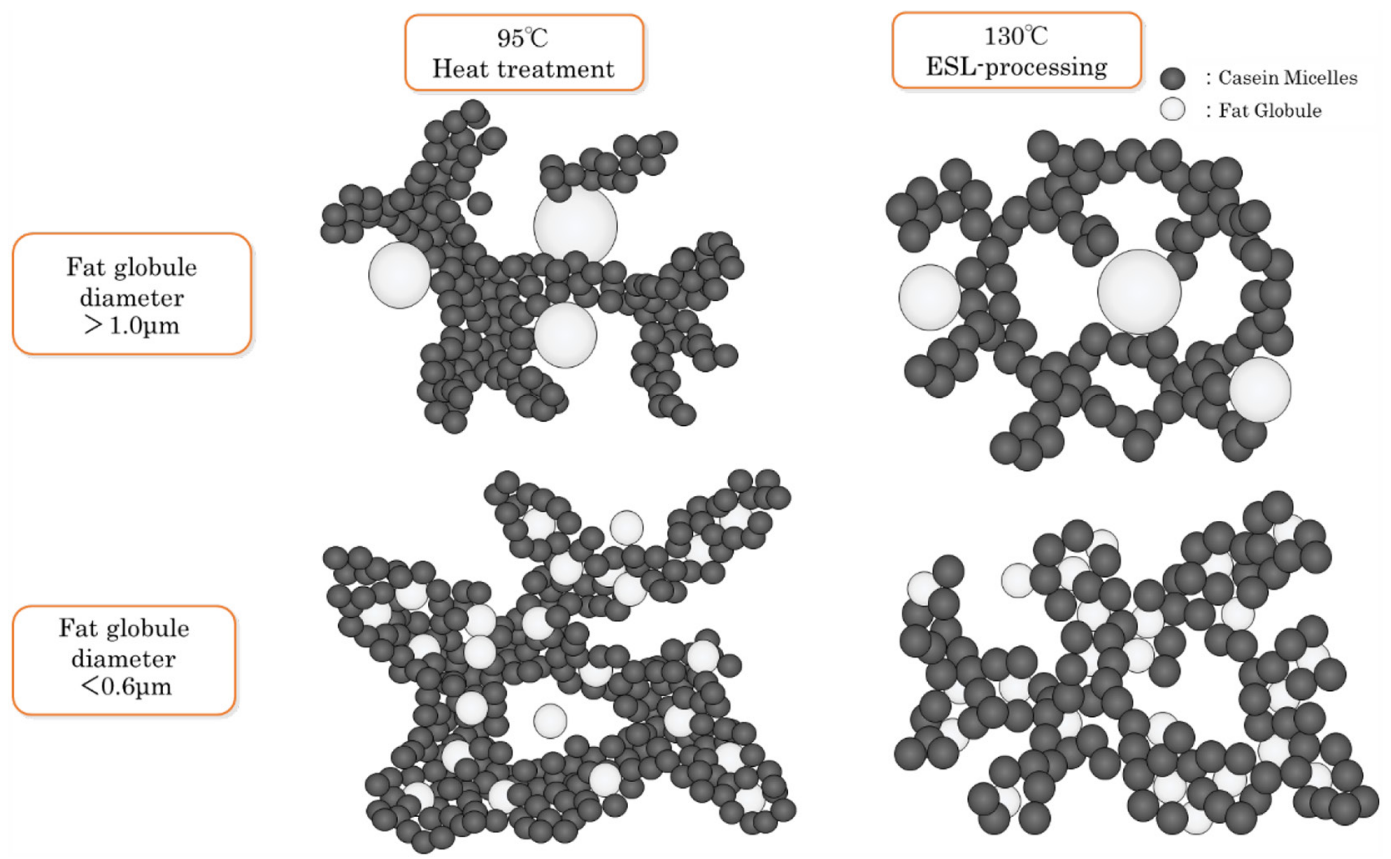

Figure 5. A model of the effects of fat globules and heat-treatment temperature on the yogurt structure, referring to our confocal laser scanning microscopy results and Michalski et al. (2002). ESL = extended shelf life.

has the advantage of improving hygiene, reducing the equipment needed by sharing a pasteurizer for milk and yogurt, and achieving a longer shelf life (Nor-Khaizura et al., 2018).

In the production of set yogurt, delayed fermentation is a serious problem that significantly reduces productivity. Tanaka et al. (2012) speculated that the high heat-resistant spores of Bacillus licheniformis that survive after a $95^{\circ} \mathrm{C}$ heat treatment of yogurt mix cause a fermentation delay. The ESL processing of yogurt mix can substantially inactivate most psychrotrophic and mesophilic spores, thereby reducing the microbial degradation risk and reducing delayed fermentation.

\section{CONCLUSIONS}

We developed a method of manufacturing set yogurt that achieves both good texture and high curd strength by focusing on the heat-treatment temperature and homogenization protocol in the yogurt manufacturing process. Other studies have shown that the yogurt curd strength was reduced by ESL processing, but our present findings demonstrated that a higher-than-conventional homogenization pressure condition increased the curd strength of the ESL-processed yogurt to a sufficient level. The yogurt made by ESL processing together with $35+5 \mathrm{MPa}$ homogenization had significantly higher scores for smoothness, fillingness, richness, mildness, and overall acceptability than those of the yogurt made under control conditions. ESL processing along with $35+5 \mathrm{MPa}$ homogenization enables the shared use of a pasteurizer for milk and yogurt and improves the efficient operation of equipment and the hygiene of the process. It can thus be said that ESL processing plus $35+5 \mathrm{MPa}$ homogenization is a manufacturing method that provides yogurt with excellent palatability, curd quality, and productivity.

\section{ACKNOWLEDGMENTS}

We thank Megumi Takai, Takayuki Toshimitsu, Kenichi Hojo, Kakuhei Isawa, Takashi Tanaka, and Munenori Fukui (Meiji Co. Ltd., Tokyo, Japan) for the many useful comments on this subject. We also thank Tomoko Ichiba, Nao Takagi, and Junko Furukawa (Meiji Co. Ltd.) for their assistance with the yogurt samples' preparation and evaluation. All authors are employees of Meiji Co. Ltd. The authors have not stated any other conflicts of interest.

\section{REFERENCES}

Aryana, K. J., and D. W. Olson. 2017. A 100-year review: Yogurt and other cultured dairy products. J. Dairy Sci. 100:9987-10013. https: //doi.org/10.3168/jds.2017-12981.

Auty, M. A., M. Twomey, T. P. Guinee, and D. M. Mulvihill. 2001. Development and application of confocal scanning laser microscopy methods for studying the distribution of fat and protein in selected dairy products. J. Dairy Res. 68:417-427. https://doi.org/ 10.1017/S0022029901004873. 
Ciron, C. I. E., V. L. Gee, A. L. Kelly, and M. A. E. Auty. 2012. Modifying the microstructure of low-fat yoghurt by microfluidisation of milk at different pressures to enhance rheological and sensory properties. Food Chem. 130:510-519. https://doi.org/10.1016/j .foodchem.2011.07.056.

Dannenberg, F., and H. G. Kessler. 1988. Effect of denaturation of $\beta$-lactoglobulin on texture properties of set-style nonfat yoghurt. 2 . Firmness and flow properties. Milchwissenschaft 43:700-704.

IDF (International Dairy Federation). 2018. IDF Factsheet, 001/2018: Heat Treatment of Milk - Overview. IDF Accessed Nov. 5, 2021. https://fil-idf.org/publications/free-of-charge/idf-factsheet-001 -2018-heat-treatment/.

Horiuchi, H., N. Inoue, E. Liu, M. Fukui, Y. Sasaki, and T. Sasaki. 2009. A method for manufacturing superior set yogurt under reduced oxygen conditions. J. Dairy Sci. 92:4112-4121. https://doi .org/10.3168/jds.2008-1747.

Karam, M. C., C. Gaiani, C. Hosri, J. Burgain, and J. Scher. 2013. Effect of dairy powders fortification on yogurt textural and sensorial properties: A review. J. Dairy Res. 80:400-409. https://doi.org/10 $1017 /$ S0022029913000514.

Krasaekoopt, W., B. Bhandari, and H. Deeth. 2004. Comparison of texture of yogurt made from conventionally treated milk and UHT milk fortified with low-heat skim milk powder. J. Food Sci. 69:E276-E280. https://doi.org/10.1111/j.1365-2621.2004.tb10998 .x.

Lee, S. J., and J. W. Sherbon. 2002. Chemical changes in bovine milk fat globule membrane caused by heat treatment and homogenization of whole milk. J. Dairy Res. 69:555-567. https://doi.org/10 .1017/S002202990200571X.

Lee, W. J., and J. A. Lucey. 2010. Formation and physical properties of yogurt. Asian-Australas. J. Anim. Sci. 23:1127-1136. https:// doi.org/10.5713/ajas.2010.r.05.

Lucey, J. A., P. A. Munro, and H. Singh. 1998. Rheological properties and microstructure of acid milk gels as affected by fat content and heat treatment. J. Food Sci. 63:660-664. https://doi.org/10.1111/ j.1365-2621.1998.tb15807.x.

Lucey, J. A., and H. Singh. 1997. Formation and physical properties of acid milk gels - A review. Food Res. Int. 30:529-542. https://doi .org/10.1016/S0963-9969(98)00015-5.

Meletharayil, G. H., L. E. Metzger, and H. A. Patel. 2016. Influence of hydrodynamic cavitation on the rheological properties and microstructure of formulated Greek-style yogurts. J. Dairy Sci. 99:85378548. https://doi.org/10.3168/jds.2015-10774.

Michalski, M. C., R. Cariou, F. Michel, and C. Garnier. 2002. Native vs. damaged milk fat globules: Membrane properties affect the viscoelasticity of milk gels. J. Dairy Sci. 85:2451-2461. https://doi .org/10.3168/jds.S0022-0302(02)74327-0.

Mottar, J., A. Bassier, M. Joniau, and J. Baert. 1989. Effect of heatinduced association of whey proteins and casein micelles on yogurt texture. J. Dairy Sci. 72:2247-2256. https://doi.org/10.3168/jds .S0022-0302(89)79355-3.
Nor-Khaizura, M. A. R., S. H. Flint, O. J. Mccarthy, J. S. Palmer, M. Golding, and A. Jaworska. 2018. 'Made-in-transit' yoghurt processing - A review of basic concepts and technological implications. Int. J. Food Stud. 7:117-135. https://doi.org/10.7455/ijfs/ 7.2.2018.a10.

Ohkubo, Y., K. Uchida, H. Motoshima, and N. Katano. 2019. Microbiological safety of UHT milk treated at $120^{\circ} \mathrm{C}$ for $2 \mathrm{~s}$, as estimated from the distribution of high-heat-resistant Bacillus cereus in dairy environments. Int. Dairy J. 91:36-40. https://doi.org/10.1016/j .idairyj.2018.12.011.

Plock, J., T. Spiegel, and H. G. Kessler. 1997. Reaction kinetics of the thermal denaturation of whey proteins in sweet whey concentrated by evaporation. Milchwissenschaft 52:678-681.

Savello, P. A., and R. A. Dargan. 1995. Improved yogurt physical properties using ultrafiltration and very-high temperature heating. Milchwissenschaft 50:86-90.

Savello, P. A., and R. A. Dargan. 1997. Reduced yogurts syneresis using ultrafiltration and very-high temperature heating. Milchwissenschaft 52:573-577.

Singh, H., M. S. Roberts, P. E. Munro, and C. T. Teo. 1996. Acidinduced dissociation of casein micelles in milk: Effects of heat treatment. J. Dairy Sci. 79:1340-1346. https://doi.org/10.3168/ jds.S0022-0302(96)76490-1.

Sodini, I., F. Remeuf, S. Haddad, and G. Corrieu. 2004. The relative effect of milk base, starter, and process on yogurt texture: A review. Crit. Rev. Food Sci. Nutr. 44:113-137. https://doi.org/10 $1080 / 10408690490424793$.

Tamime, A. Y., and R. K. Robinson. 2007a. Heat treatment. Pages 67-85 in Yoghurt Science and Technology. 3rd ed. Woodhead Publishing Ltd.

Tamime, A. Y., and R. K. Robinson. 2007b. Homogenization. Pages 61-67 in Yoghurt Science and Technology. 3rd ed. Woodhead Publishing Ltd.

Tamime, A. Y., and R. K. Robinson. 2007c. Fermentation process. Pages 85-96 in Yoghurt Science and Technology. 3rd ed. Woodhead Publishing Ltd.

Tanaka, T., A. Ito, and H. Kamikado. 2012. Control of Bacillus licheniformis spores isolated from dairy materials in yogurt production. Biocontrol Sci. 17:169-173. https://doi.org/10.4265/bio.17.169.

Teo, C. T., P. A. Munro, and H. Singh. 1997. Variation of water-holding capacity and mechanical properties between the particle size fractions of mineral acid, lactic and rennet casein curds. J. Dairy Res. 64:581-589. https://doi.org/10.1017/S0022029997002446.

\section{ORCIDS}

T. Ichimura ๑ https://orcid.org/0000-0002-8035-8410 